Research Article

\title{
Experimental Study on the Relationship between Compression Stability and Deformation Localization of Viscous/Brittle Rock-Like Materials
}

\author{
Xiangfeng Lv, ${ }^{1}$ Yahan Yang $\mathbb{D}^{1},{ }^{1}$ Yan Chen, ${ }^{2}$ Nianjin Wang, ${ }^{3}$ Min Yang, ${ }^{3}$ Ying Shao, ${ }^{3}$ \\ and Jiaxing $\mathbf{L i}^{3}$ \\ ${ }^{1}$ School of Civil and Resource Engineering, University of Science and Technology Beijing, Beijing 100083, China \\ ${ }^{2}$ Beijing Guodian Jingwei Engineering Technology Co. Ltd., Beijing 100083, China \\ ${ }^{3}$ Power China Road Bridge Group Co. Ltd., Beijing 100032, China
}

Correspondence should be addressed to Yahan Yang; 943662177@qq.com

Received 15 May 2021; Accepted 28 July 2021; Published 5 August 2021

Academic Editor: Hamed Akhavan

Copyright (C) 2021 Xiangfeng Lv et al. This is an open access article distributed under the Creative Commons Attribution License, which permits unrestricted use, distribution, and reproduction in any medium, provided the original work is properly cited.

Rock-like materials often exhibit irregular failure deformation under long-term service conditions, and the deformation and failure of asphalt and concrete materials is a serious problem that leads to subgrade failure. In this study, two different viscous/ brittle rock-like materials were prepared by the in situ loading and optical speckle synchronous monitoring test method, and the evolution characteristics of the deformation field were studied during compression. The formation process of the compression deformation localization of rock-like materials and their relationship with stability were analyzed. A quantitative description of the compression deformation stage and localization characteristics of the viscous/brittle rock-like materials is presented. The results can be summarized as follows. At the initial stage of compression, the deformation localization zone of viscous/brittle rocklike materials begins to expand from the middle area to the surrounding area. Preliminary results of the deformation localization of the linear elastic deformation stage were obtained. The failure cloud image is completely formed at the peak, which is consistent with the failure physical map. The deformation process of compression can be quantitatively described using the deformation localization characteristics of rock-like materials.

\section{Introduction}

The deformation and failure law of rock correlates with rock engineering quality, life span, and dynamic disasters [1]. In the long-term service state, rock failure is often closely related to the development of rock deformation localization. It is of great significance to study the deformation localization of rocks to improve the stability of the service rock. Many local and foreign scholars have carried out extensive studies on the localization deformation of rock materials. For instance, Benaboud et al. [2] identified different fatigue stages of asphalt concrete under bending loads using the evolution of acoustic emission activity over time. Sakharuk et al. [3] proposed a rough surface image adaptive digital speckle method to measure the surface displacement field of hard aluminum beams with transverse fatigue cracks under threepoint loading. Zhang et al. [4] conducted uniaxial compression tests on cement specimens. The analyzed cracks began to develop from the short axis, and the crack propagation direction changed from perpendicular to the crack surface to parallel to the principal stress direction, which provided a basis for the development process of rock mass cracks. Sun et al. [5] used experiments and numerical simulations to find that the initial damage of rock mass has a significant impact on the strength and failure process of fractured rock mass. To study the whole process of rock failure in compression test, 3D digital speckle technology can be used to clearly reflect the occurrence and evolution of internal cracks [6-12]. By studying the fracture development process of rock-like $[13,14]$ and $\operatorname{rock}[15,16]$, the 
macroscopic damage characteristics are obtained. By studying the localization characteristics of rock [17], soil [18], and gneiss [19], the critical failure state is obtained. Yuan et al. [20] and Han et al. [21] used CT images to provide a visual method for studying the meso-scale deformation and failure mechanism of concrete and defined the corresponding characteristics of crack development and deformation and failure stage in the CT scale. Xu et al. [22] studied the evolution of rocks from a localized strain area to a narrow strain localization zone during the strain softening stage, forming a macroscopic fracture surface through the specimen, and found that the residual strength deformation is mainly concentrated in the localization zone. Zhang et al. [23] used the digital speckle light method to test the deformation localization of soft-rock specimens of mudstone and sandstone with two different lithologies in uniaxial compression and found that the onset time of soft-rock deformation localization was earlier than that of brittle rock. Song et al. [24] used the white-light digital speckle observation method to study the evolution characteristics of the deformation field of red sandstone during deformation and failure processes via uniaxial compression tests. The study concluded that the bearing capacity of the rock specimens after the loading peak was mainly affected by the displacement evolution of the deformation localization zone. Yang et al. [25] experimentally investigated the evolution of nonuniform deformation of granite specimens subjected to uniaxial cyclic loading and unloading. The study concluded that the extrusion displacement and the width of the localization zone increased with an increase in stress and the number of cycles after the localization of the specimen. Pan and Yang [26] used the white-light digital speckle correlation method to study the initial time, evolution process, and width of the localized zone of rock deformation and failure.

In this study, the uniaxial compression test method was used to simulate the deformation evolution test of two different types of rock-like specimens: asphalt and concrete. The entire instantaneous process of rock-like failure under in situ loading was recorded. A CCD camera was used to record the speckle image of the entire rock loading process in the rock deformation localization test. MAT$\mathrm{LAB}$ software was used for data processing to produce rock deformation localization zone cloud images, and to observe the rock specimen deformation localization evolution law. The failure stage of rock-like specimens under in situ loading was analyzed based on the evolution process of the deformation localization zone. According to the evolution process of the deformation localization zone of rock-like materials, the failure stage subjected to in situ loading is analyzed, and the entire process of compression deformation is quantitatively described by the deformation localization characteristics of rock-like materials. This study has far-reaching significance for synchronous monitoring of subgrade failure in long-term service conditions.

\section{In Situ Loading and Optical Speckle Synchronous Monitoring Test}

2.1. In Situ Loading and Optical Speckle Synchronous Monitoring System. The test data acquisition system consists of a loading system and a digital speckle image acquisition system, as shown in Figure 1.

The test loading system is a RLJW-2000 hydraulic servo testing machine, and uniaxial compression loading was carried out using the displacement control method.

The digital speckle image acquisition system is composed of a coal rock surface speckle image acquisition system built using a CCD camera and the calculation program of the digital speckle correlation method to analyze the surface deformation field of rock specimens. The acquisition rate is 5 frames per second, the image resolution is 1600 pixels $\times 1200$ pixels, and the surface resolution is $0.1136 \mathrm{~mm} /$ pixel.

Before the test, the rock specimen was processed into a cylinder, and the upper and lower bottom surfaces of the specimen were polished to ensure a smooth end face. A sufficient amount of Vaseline was uniformly applied on both sides, and a layer of preservative film was applied to reduce the friction resistance. White paint was sprayed on the surface of the specimen, so that white paint particles were randomly scattered on the surface of the specimen to create an artificial speckle field.

The loading system and the digital speckle acquisition system were calibrated, so that the time of data collection by the entire test system during the test was consistent. At the beginning of the test, the loading device and the digital speckle image acquisition system were triggered simultaneously. The test data for the entire loading process were collected until the specimen was destroyed. After the loading test, the smooth surface and rupture surface of the coal body were scanned using an electron microscope scanner, and the scanning results under different magnifications were obtained. Finally, the test data were analyzed and processed.

\subsection{Parameters of Viscous/Brittle Rock-Like Materials.} Test specimens of asphalt and concrete with two different types of rock materials were prepared, with 50 specimens in each group. Each specimen section was $50 \mathrm{~mm} \times 50 \mathrm{~mm}$, and the height was $100 \mathrm{~mm}$. The artificial speckle field was prepared by spraying paint on the surface of the specimen, and the loading rate was set to $0.5 \mathrm{~mm} / \mathrm{min}$. A CCD camera was used to obtain the surface image of the specimen. The image data were collected at five frames per second for the rock specimens, as shown in Figure 2.

\subsection{Analysis of Test Results of Viscous/Brittle Rock-Like} Materials. A group of 50 asphalt specimens were tested based on the relationship between service stability and deformation localization of viscous/brittle rock-like materials. A total of 5515 speckle images were collected using the image system of each specimen during the loading process. A group of 50 concrete specimens were also tested, and 2165 speckle images were collected in each specimen loading process image system. Three representative data items were selected for each 


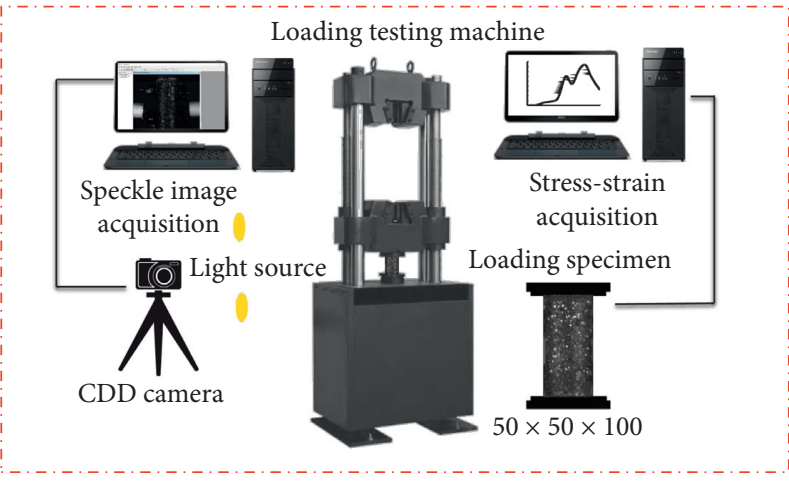

Figure 1: In situ loading and optical speckle synchronous monitoring test device.

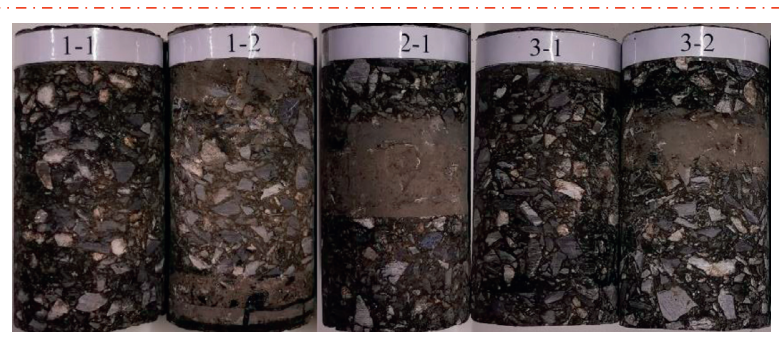

(a)

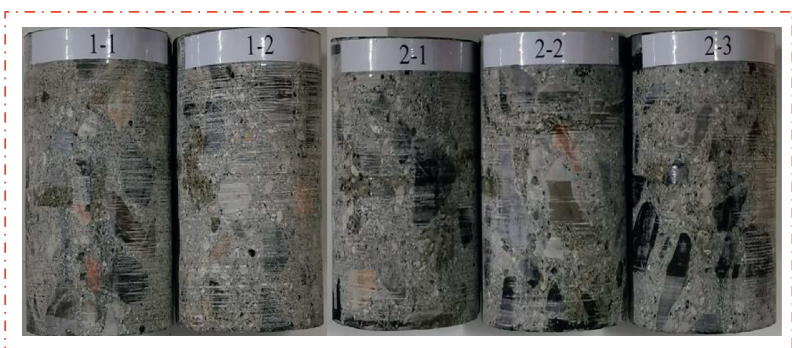

(b)

Figure 2: Physical map of viscous/brittle rock specimen. (a) Asphalt. (b) Concrete.

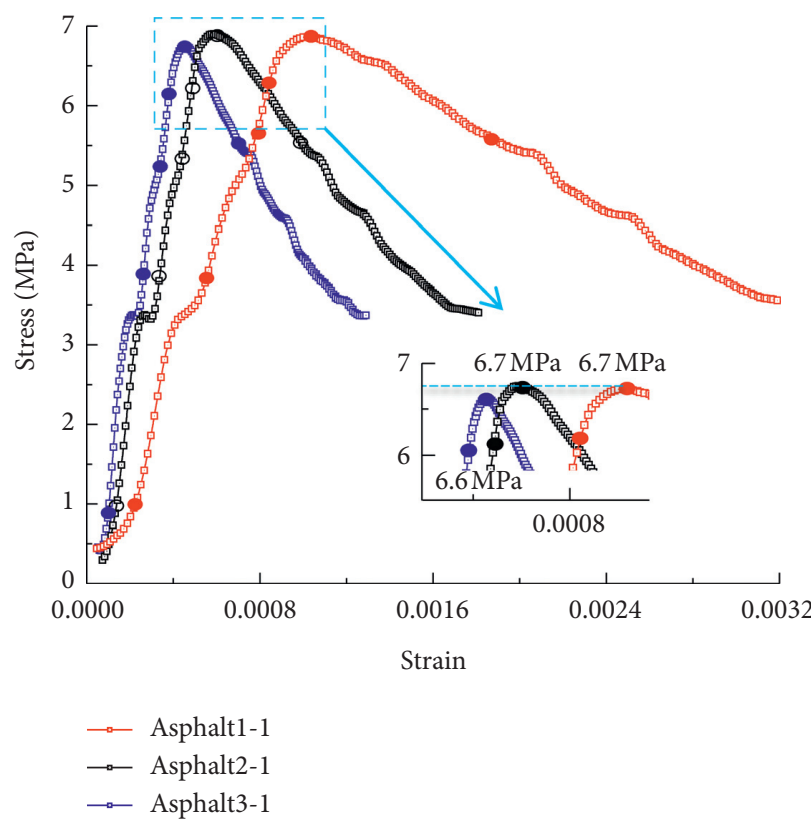

(a)

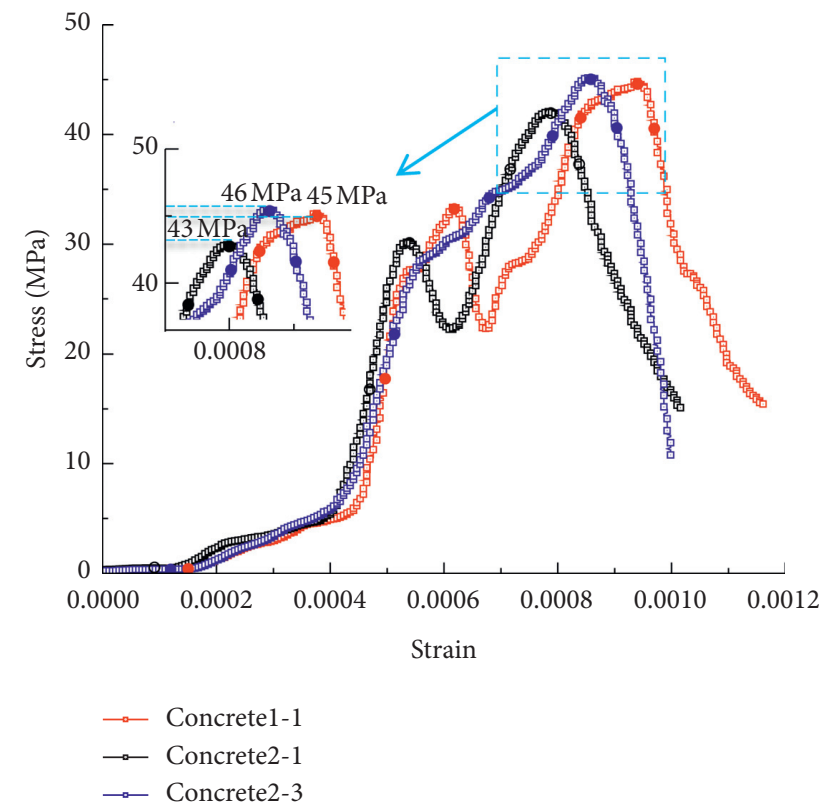

(b)

Figure 3: In situ loading stress-strain curves of rock-like specimens. (a) Asphalt specimen. (b) Concrete specimen.

type of rock for analysis and comparison owing to space limitation. The in situ loading stress-strain curve is shown in Figure 3. Six identification points were selected for each specimen based on the loading curves. The in situ loading stress-strain curve of the rock-like specimen is as follows:
Marking points 1-6 appear in the order shown in Figure 3. The stress-strain curve of the asphalt specimen is divided into two stages as shown in figure. Marking points 1, 2 , and 3 are located in the linear elastic deformation stage. The loading time in the linear elastic deformation stage is 
short, accounting for approximately $43 \%$ of the total loading time, and the stress-strain fluctuation increases. Marking point 4 belongs to the peak point of the specimen loading, and the postpeak stage is the viscosliding deformation stage. The instability process is relatively slow, and the bearing capacity remains large. The stress-strain curve of the concrete specimen is divided into three stages as shown in Figure 3. Marking point 1 is the initial compaction stage, marking point 2 is located in the linear elastic deformation stage, marking point 3 is the second peak, marking point 5 is the loading peak at the initial compaction stage, and the elastic deformation stage of the peak is approximately $81 \%$ of the total loading time of the specimen. The rapid fluctuation of the post peak stress-strain curve decreases to the brittle instability stage.

\section{Localization Characteristic Analysis of Compression Deformation}

The in situ loading and light speckle synchronous monitoring test stress-strain curves are shown in Figure 3. Rocklike materials often exhibit irregular failure deformation in the long-term service state. This study selected a group of representative test data for each rock type, the deformation localization cloud map a-f corresponding to identification points 1-6, and analyzed the deformation localization results of rock-like specimens under in situ loading, owing to space limitation.

\subsection{Analysis of Deformation Localization Characteristics of} Asphalt Specimen. The failure process of a group of 50 asphalt specimens in the in situ loading test was studied. In view of space limitations, a group of typical deformation localization characteristics of asphalt specimen was selected for a specific analysis. The deformation localization cloud map corresponding to the speckle scanning image of markers 1-6 was generated after data processing using MATLAB. The deformation localization cloud maps in Figures $4(\mathrm{a})-4(\mathrm{f})$ of the asphalt specimen correspond to markers 1-6 as shown in Figure 4. At the beginning of loading, the stress reaches $0.8 \mathrm{MPa}$, the speckle interference fringes fluctuate uniformly, and the deformation localization band is initially formed. With continuous loading, the speckle interference fringes of the specimen develop steadily in the linear elastic deformation stage, and the stress concentration areas in the middle and bottom appear. The deformation localization zone gradually forms, and the peak cloud images correspond to each other. When the stress reaches the peak value of $6.7 \mathrm{MPa}$, the maximum shear strain is $0.022 \mathrm{~mm}$, and the deformation localization zone tends to be stable. Multiple stress concentration areas such as the middle, top, and bottom appear along the $45^{\circ}$ direction of the diagonal and develop from the stress concentration area to its surrounding areas.

The preliminary formation in Figure 5(a), failure diagram in Figure 5(b), and failure nephogram in Figure 5(c) of the deformation localization zone of the asphalt specimen during the in situ loading process are shown as follows.
Figure 5(a) shows that when the stress of marker point 3 reaches $5.3 \mathrm{MPa}$, the maximum shear strain is $0.0018 \mathrm{~mm}$, and the stress concentration area preliminarily develops. The result shows that the preliminary forming cloud image of the deformation localization zone is consistent with the deformation localization cloud image of specimen failure. Figure 5(c) shows that when the stress of marker point 5 reaches $6.7 \mathrm{MPa}$, the maximum shear strain value is $0.022 \mathrm{~mm}$. Under the action of uniform force during in situ loading, the deformation localization zone expands from the stress concentration area to the surrounding, and the deformation localization zone was along the diagonal $45^{\circ}$ to form the fracture zone. The results show that the failure physical map of the specimen in Figure 6 corresponds to the failure cloud map of the deformation localization zone. After the failure of the specimen, obvious stick-slip deformation occurs, and multiple irregular cracks appear on the surface, but the cracking site is still partially connected. With an increase in the cracking site, the transverse width of the specimen gradually increases, and a high number of local spalling and adhesions are found on both sides of the specimen. The diagonal line of $45^{\circ}$ forms multiple inclinations through cracks and continues to develop and expand, which is necessary for the failure of the specimen.

\subsection{Analysis of Deformation Localization Characteristics of} Concrete Specimen. In this study, the failure process of a group of 50 concrete specimens in situ loading tests was investigated. In view of the space limitation, a group of typical concrete specimen deformation localization results were selected for a specific analysis. The deformation localization cloud map corresponding to the 1-6 speckle scanning image of the identification point was generated after MATLAB data processing. The following diagram shows that the deformation localization cloud map in Figures $7(\mathrm{a})-7(\mathrm{f})$ of the concrete specimen corresponds to identification points 1-6. At the beginning of loading, the specimen enters the initial compaction stage and remains for a long time. At this stage, the speckle interference fringes are in disorder and fluctuate, and a deformation localization zone is initially formed. As loading continues, the specimen enters the stage of linear elastic deformation, the deformation localization zone of the concrete specimen gradually develops, and the speckle interference fringe begins to expand from the middle of the two sides. When the stress reaches the second peak of $30 \mathrm{MPa}$, the maximum shear strain is $0.0055 \mathrm{~mm}$, a stress concentration phenomenon occurs in the upper and lower bottom, and the deformation localization zone tends to develop stably. The upper and lower bottom start breeding evolution, and cracks from the bottom begin to extend along the pressure axis upward development. When the stress reaches a peak value of $41 \mathrm{MPa}$, the maximum shear strain is $0.025 \mathrm{~mm}$, and the deformation localization zone develops completely on both sides to form speckle cracks through the specimen.

The initial development of the deformation localization zone in Figure 8(a), failure nephogram in Figure 8(b), and failure entity diagram in Figure $8(c)$ of the concrete 


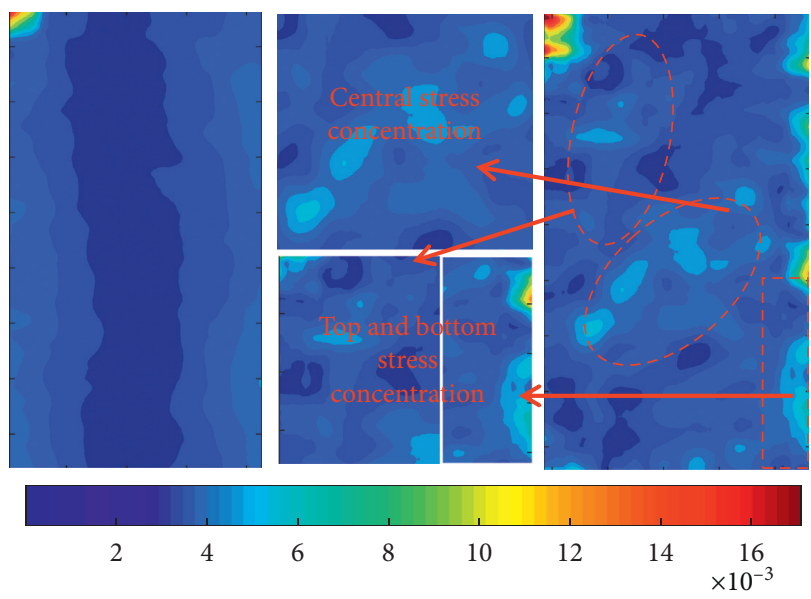

(a) (b)
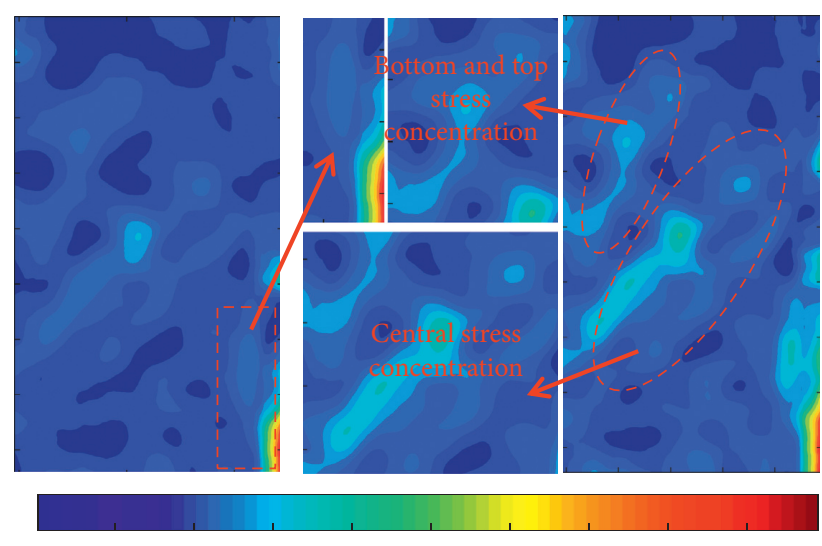

2

(c) (d)

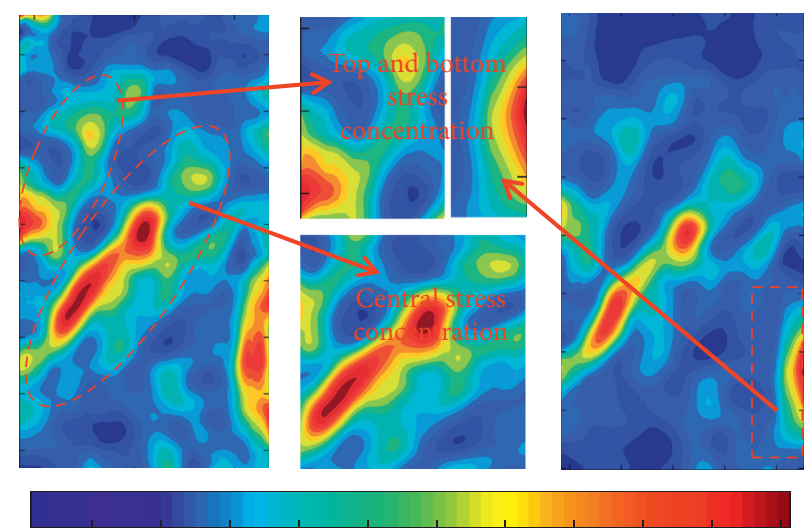

$\begin{array}{lllllllllll}0.002 & 0.004 & 0.006 & 0.008 & 0.01 & 0.012 & 0.014 & 0.016 & 0.018 & 0.02 & 0.022\end{array}$

(e)

(f)

Figure 4: Cloud image of deformation localization zone of asphalt specimen. (a) $0.8 \mathrm{MPa}$, (b) $3.8 \mathrm{MPa}$, (c) $5.3 \mathrm{MPa}$, (d) $6.2 \mathrm{MPa}$, (e) $6.7 \mathrm{MPa}$, (f) $5.6 \mathrm{MPa}$.

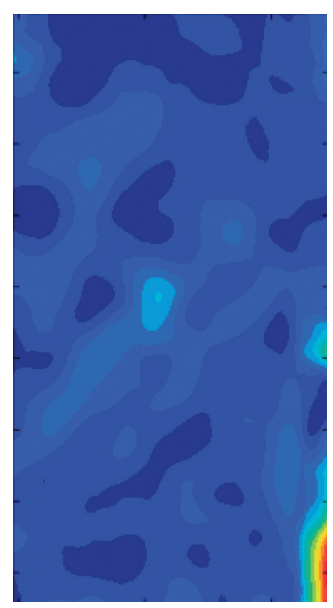

(a)

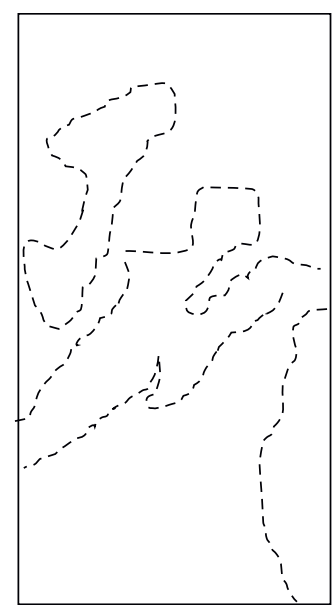

(b)

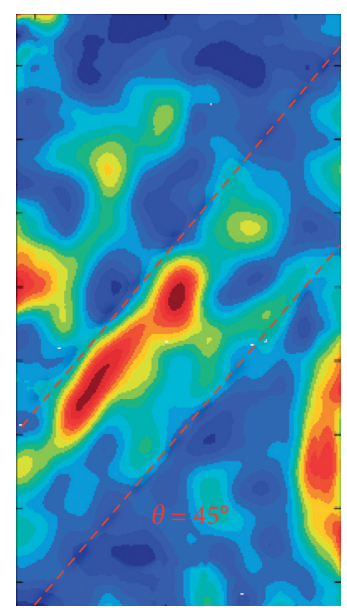

(c)

Figure 5: Localization diagram of failure deformation of asphalt specimen. (a) Preliminary. (b) Damage. (c) Cloud map.

specimen during the in situ loading process are shown as follows. The speckle interference fringes at sign point 2 Figure 8 (a) gradually tend from disorder to stable, and the maximum shear strain is $0.0055 \mathrm{~mm}$. The stress concentration zone is initially generated at the bottom, which extends upward along the pressure axis. Figure 8(c) shows 


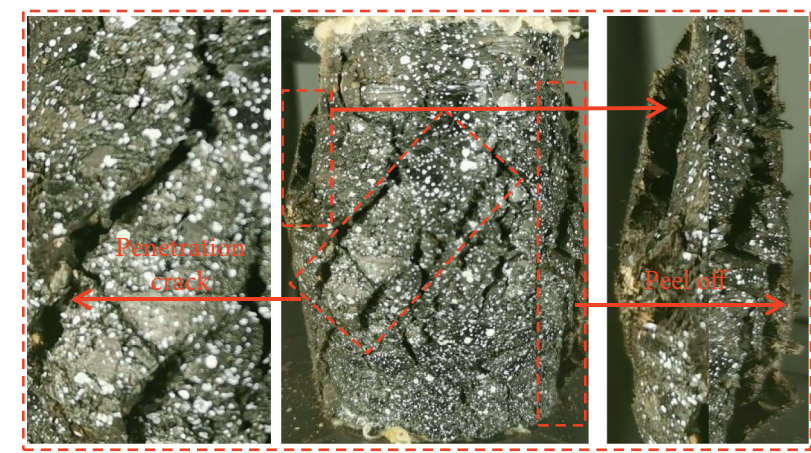

FIgURE 6: Material map of asphalt specimen failure.

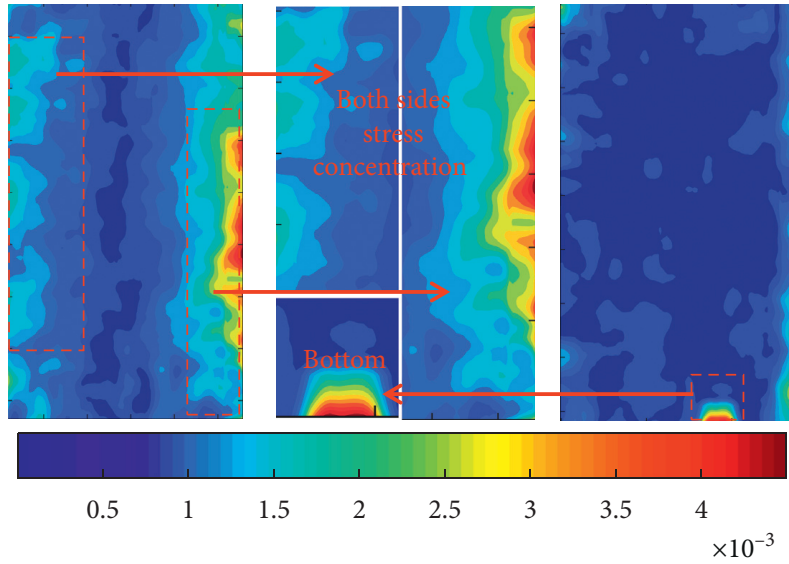

(a) (b)
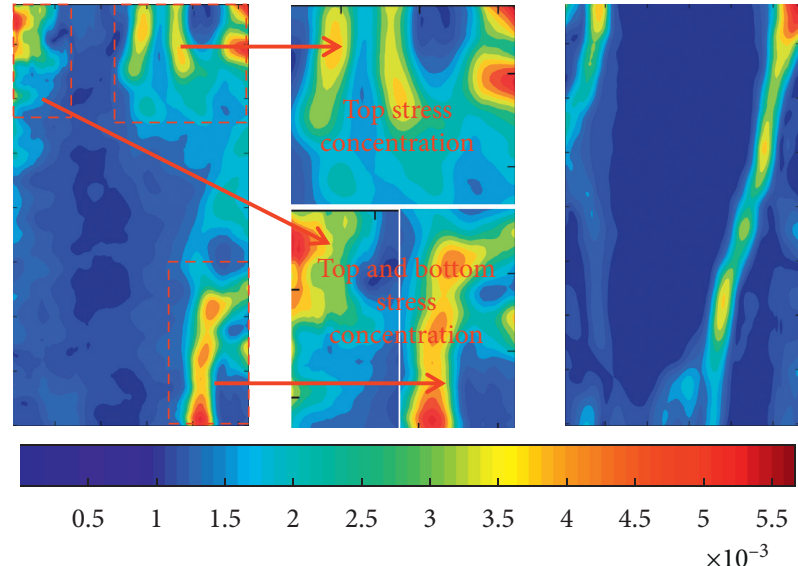

(c)

(d)

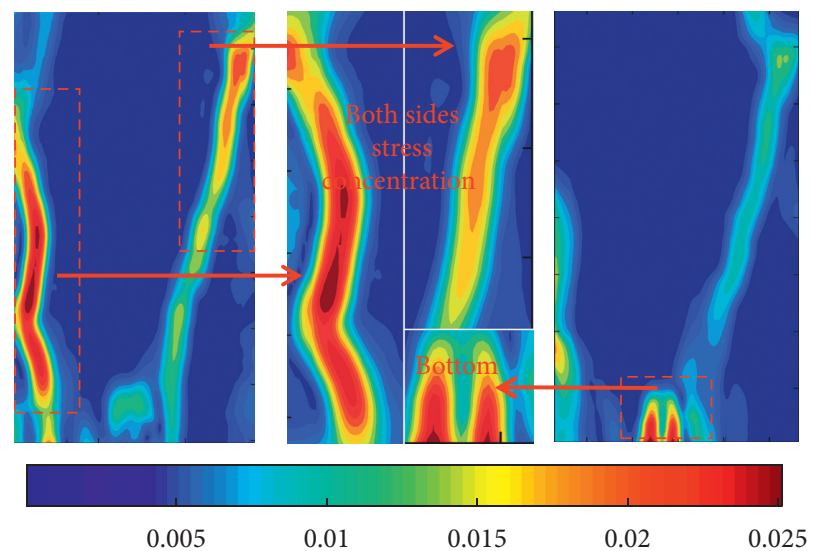

(e)

(f)

Figure 7: Cloud image of the deformation localization zone of the concrete specimen. (a) $1 \mathrm{MPa}$, (b) $17 \mathrm{MPa}$, (c) $30 \mathrm{MPa}$, (d) $37 \mathrm{MPa}$, (e) $43 \mathrm{MPa}$, (f) $37 \mathrm{MPa}$.

the peak stress stage for identification point 5 ; both sides produce an obvious stress concentration area, and the deformation localization zone forms completely on both sides through the specimen. In the process of in situ loading, brittle splitting occurs in the concrete specimen, and the deformation localization zone develops significantly on both sides. The results show that the failure physical map of the specimen in Figure 9 corresponds to the splitting failure cloud map (c) of the deformation localization zone. During the in situ loading process, the deformation localization zone of the concrete specimen gradually spreads from the top of the bottom to the middle. The stress concentration on both sides is significant, and the development along the pressure axis exhibits a splitting trend. Changes in brittleness occur after failure of the specimen, and many small cracks are observed on the surface. There are obvious long straight cracks on both sides, running through the internal surface of the specimen. Y-type cracks are generated at the top, and 


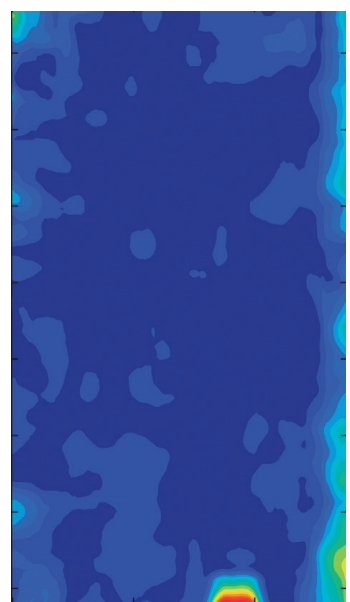

(a)

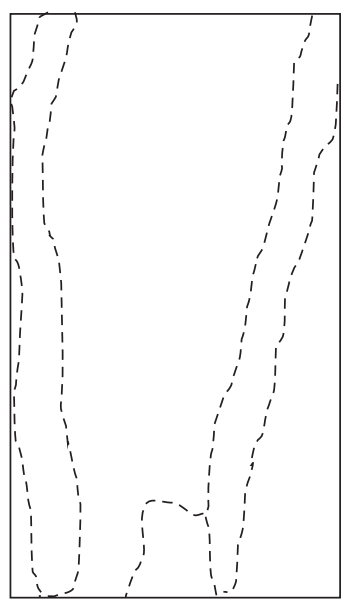

(b)

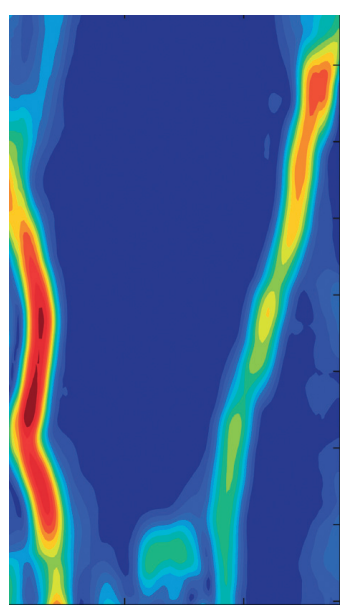

(c)

Figure 8: Localization diagram of failure deformation of concrete specimen. (a) Preliminary. (b) Damage. (c) Cloud map.

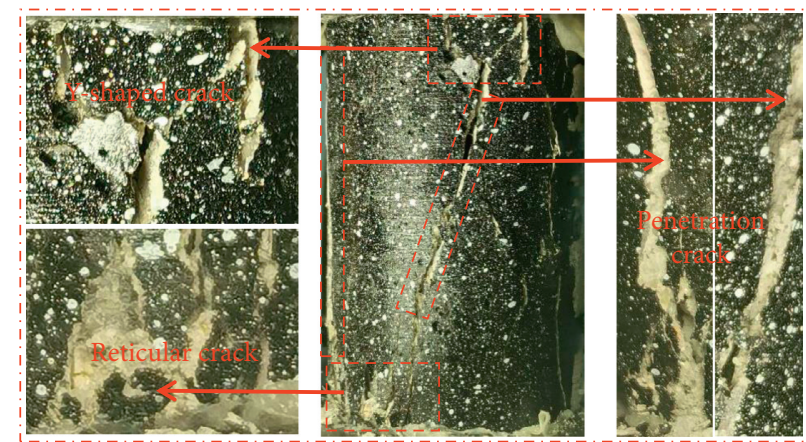

Figure 9: Material map of concrete specimen failure.

local spalling mesh cracks are generated at the bottom. The peak value shows obvious brittleness. The bearing capacity of the specimen decreases rapidly, and the value reaches the specimen failure value.

\subsection{Comparative Analysis of Deformation Localization} Characteristics of Viscous/Brittle Rock-Like Materials. The internal cracks of the asphalt specimens change with the loading process. In the linear elastic deformation stage, the voids inside the asphalt specimen structure are gradually compacted, and the porosity decreases. The specimen continues to accumulate deformation, and the bearing capacity increases, thereby indicating an elastic property. With the continuous loading, the internal stress concentration area of the asphalt preferentially produces microcracks, and the microcracks extend to the surrounding areas, forming macroscopic through cracks. In the failure stage, many irregular macroscopic cracks exist on the surface, and adhesions are still present in some cracking areas. With the continuous loading, the transverse width of the specimen increases gradually with the increase in the cracking site. A large number of local spalling and adhesions are found on both sides of the specimen. Multiple macroscopic penetrating cracks are formed in the $45^{\circ}$ stress concentration area of the diagonal. According to the evolution characteristics of the deformation localization of viscous/brittle rock-like materials under in situ loading, asphalt materials exhibit stick-slip failure, and the deformation localization zone develops from multiple stress concentration areas in the middle to around. The specimen has a multichannel penetrating crack along the diagonal direction of $45^{\circ}$. Local spalling and adhesion occur on both sides, and the bearing capacity decreases uniformly and slowly until complete failure of the specimen occurs.

The internal cracks of the concrete specimens change according to the loading process. In the initial compaction stage, the internal small space of concrete specimens is gradually closed under in situ loading, resulting in nonlinear deformation. In the early stage of linear elastic deformation, the internal stress concentration area of the concrete specimen under in situ loading preferentially generates microcracks, and the microcracks extend around. In the late stage of linear elastic deformation, unstable fractures are developed within the concrete specimens, and the qualitative changes of internal microcracks indicated that the microcracks began to penetrate and expand to form a hole through the specimen. Furthermore, the cracks continued to develop and rupture the specimen. In the failure stage, due to the continuous compression on both sides of the concrete, 
obvious longitudinal long and straight cracks run through the internal surface of the specimen, Y-type cracks appear at the top, and local spalling network cracks appear at the bottom. The concrete material exhibits obvious brittle failure. The stress concentration area first appears on the upper and lower bottom surfaces. The local deformation zone develops gradually along the pressure axis from the stress concentration area. After the internal cracks of the specimen gradually develop into longitudinal penetrating cracks, the bearing capacity of the concrete specimen decreases rapidly until specimen failure occurs.

Although asphalt and concrete are different rock-like materials, the development of macroscopic cracks is observed using digital speckle images during in situ loading. The deformation localization zone of the specimen in the elastic deformation stage can be preliminarily developed and formed to predict the final failure situation. When the stress of the specimen reaches its peak value, the development of the deformation localization zone is consistent with the loading failure physical map.

\section{Correlation Analysis between Rock Types and Deformation Localization Stage}

According to the above analysis, the development process of the deformation localization zone in the early peak of viscous/brittle rock-like materials is similar, and the deformation localization zone has different evolution characteristics according to the failure type of rock-like materials. In view of the space limitation, this section presents a selected group of representative specimens in each rock type to analyze the correlation between the compression deformation stage and the localization characteristics of different types of rock under in situ loading.

4.1. Phase Correlation Analysis of Asphalt Material Deformation Localization. The stress-strain curve of the asphalt specimen is divided into two stages: elastic deformation stage (I) and stick-slip failure stage (I). After the peak failure of the specimen, a viscous-slip deformation and a linear slow failure occur, which means that the specimen loses its bearing capacity.

The asphalt specimen in situ loading process and the deformation localization zone stress and strain correlation analysis, obtained as shown in Figure 10 for the in situ loading process of asphalt specimen deformation localization curve, are selected. At the initial stage of the curve, the stress and strain increase simultaneously, which is the linear elastic deformation stage (I). The curve increases linearly with a sawtooth shape; the strain growth is smaller, whereas the stress growth is larger. In the early stage of the linear elastic deformation stage (I), the speckle interference fringe tends to be stable. The deformation localization zone expands steadily to the surrounding area owing to the uniformly distributed force on the rock. With gradual development of the deformation localization of the specimen under loading, the deformation localization zone is initially formed in the late stage of the linear elastic deformation

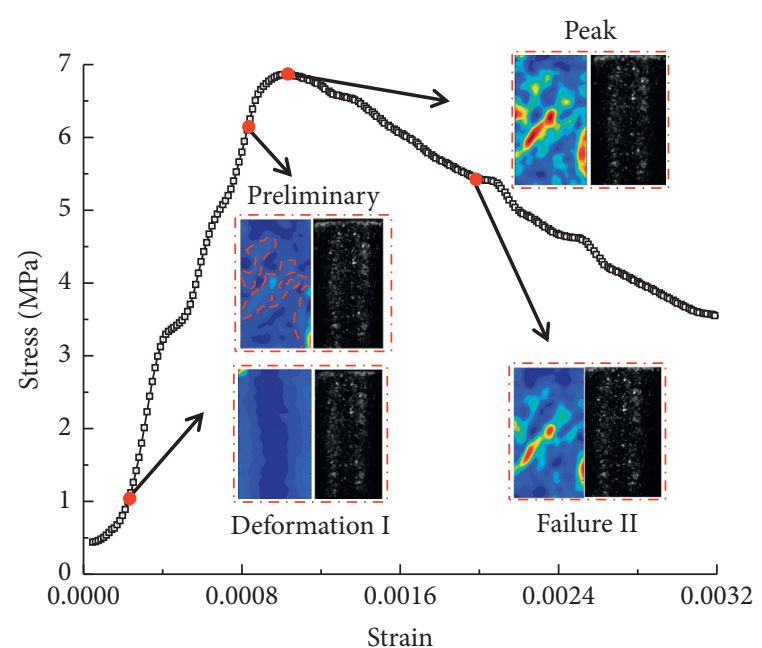

FIGURE 10: Relationship curve of deformation localization of asphalt specimen.

stage (I), forming the foundation area of the deformation localization zone when failure occurs and expanding from the stress concentration area to the surrounding area. When the stress reaches the peak value, the deformation localization zone develops completely as a diagonal of $45^{\circ}$ to form a fracture zone, and the small cracks in the specimen form inclined penetrating cracks. After the stress reaches its peak, it begins to decrease slowly in a serrated shape, which is the stage of stick-slip failure (II). At this time, the stress reduction rate is far less than the stress growth rate in the elastic deformation stage (I). The strain increases continuously, and the irregular cracks on the surface of the asphalt specimen increase continuously. The longitudinal shrinkage and lateral expansion of the specimen are large, and the integrity gradually decreases with the loss of the bearing capacity of the specimen.

\subsection{Phase Correlation Analysis of Deformation Localization of} Concrete Materials. The stress-strain curve of the concrete specimen is divided into three stages: initial compaction stage (I), linear elastic deformation stage (II), and brittle failure stage (III). Obvious brittle failure occurs after the peak failure of the specimen, and the bearing capacity of the specimen decreases rapidly, and the value is lost.

The in situ loading process of the concrete specimen was selected, and stress-strain correlation analysis of the deformation localization band was performed to obtain the deformation localization relationship curve of the concrete specimen in the in situ loading process, as shown in Figure 11. In the initial stage of the curve, the stress increases slowly, and the strain begins to grow, which is the initial compaction stage (I). In the initial compaction stage (I), the deformation localization zone initially forms from the middle area to the periphery. In the second stage of the curve, the stress and strain increase simultaneously, and the curve shows a jagged linear fluctuation, which is the linear elastic deformation stage (II). The deformation localization zone develops gradually, and the stress concentration area 


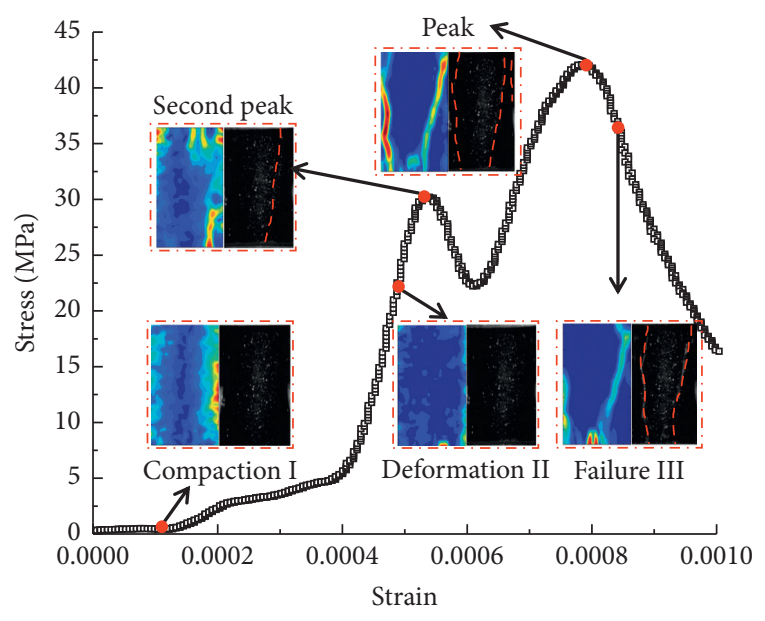

FIGURE 11: Relationship curve of deformation localization of concrete specimen.

first appears at the bottom. The strain growth is small, the stress growth reaches the second peak, and the deformation localization zone tends to be stable. The stress concentration area appears on the upper and lower surfaces, and the surface of the loading part has small cracks that have not yet penetrated. The stress fluctuation increases to the peak value, and an obvious stress concentration phenomenon occurs on both sides of the deformation localization zone. The stress concentration area runs through the two sides of the specimen in a long strip, and many irregular fine cracks on the surface of the original specimen are loaded to form long straight large cracks. In the third stage, the stress begins to decrease rapidly after the stress reaches the peak value, which is the brittle failure stage (III). In this case, the stress reduction rate is slightly greater than the stress growth rate in the linear elastic deformation stage, and the strain continues to increase. Many irregular cracks appear on the surface of the asphalt specimen and begin to penetrate the specimen. The volume change is small, and the specimen quickly loses its bearing capacity.

\subsection{Stage Correlation Analysis of Deformation Localization of} Rock-Like Materials. During the in situ loading process, the maximum bearing capacity of the asphalt specimen is small, the peak stress is $6.6 \mathrm{MPa}$, and the loading time is longer than $890 \mathrm{~s}$. The bearing capacity of the asphalt specimen with stick-slip deformation after the peak decreases slowly, and the transverse width increases significantly and decreases longitudinally. It still has a certain bearing capacity for a long time, and the failure time after the peak accounts for $57 \%$ of the total loading time. There is an initial compaction stage for the concrete specimen, which accounts for $15 \%$ of the total loading time and has a large peak stress of $46 \mathrm{MPa}$. In the online elastic deformation stage, the specimen first reaches the second peak, and stress fluctuation increases and then reaches its peak. The failure time after the peak accounts for $19 \%$ of the total loading time, which has obvious brittleness. There is no obvious change in the volume of the specimen during in situ loading.
During the in situ loading process, the continuous compression of the upper and lower bottom surfaces leads to the formation of a stress concentration area in the specimen under load. The stress concentration area first produces microcracks, and the crack evolves through the specimen with the continuous loading. In the in situ loading process, the rock-like materials are divided into different deformation localization stages according to the failure state of rocklike materials. The crack evolution process corresponds to the deformation localization stage. However, the failure of rock-like materials cannot be observed macroscopically. Digital speckle correlation technology is used to obtain a deformation localization cloud map corresponding to the development of cracks in the specimen, and the failure of rock-like materials is then observed. According to a study on the correlation between deformation localization and the loading stage of in situ loading and optical speckle synchronous monitoring test of viscous/brittle rock-like materials, the failure process of viscous and brittle rock-like materials under compression is stage-dependent with its deformation localization characteristics. A digital speckle image can be used to determine the compression curve stage of a specimen. At the initial stage of compression, there are small cracks in the original part of the specimen, and the deformation localization zone is initially formed from the middle area to the surrounding area. In the linear elastic deformation stage, the initial deformation localization cloud image corresponds to the peak failure cloud image. At the peak, the original part of the specimen has a penetrating macroscopic crack, and the failure cloud image is essentially consistent with the failure entity image. The deformation localization characteristics of rock-like materials can be used to quantitatively describe the compression deformation process.

The random points of the road subgrade in the long-term service state were selected, and core drilling sampling was conducted. The damage of the subgrade was obtained via in situ loading and an optical speckle synchronous monitoring test, and then the road subgrade was scientifically maintained with different pertinences so as to realize the synchronous detection of the road subgrade in the long-term service state.

\section{Conclusions}

(1) At in situ loading and light speckle synchronous monitoring test loading rate of $0.5 \mathrm{~mm} / \mathrm{min}$, the peak stress of asphalt specimen is $6.6 \mathrm{MPa}$, and the peak failure time accounts for $57 \%$ of the total loading time, showing a stick-slip failure. The peak stress of concrete specimen is $46 \mathrm{MPa}$, and the postpeak failure time accounts for $19 \%$ of the total loading time, showing brittle failure.

(2) The asphalt specimen in the in situ loading test exhibits viscous-slip failure based on the evolution and forming characteristics of the deformation field in the entire process of compression loading of viscous rock-like materials. The stress concentration area generated in the linear elastic deformation stage 
starts the peak value development of the stress to be fully formed from the middle. After the peak, the transverse width of the creep phenomenon increases significantly and decreases longitudinally. Multichannel penetrating cracks are generated along the diagonal direction of $45^{\circ}$, and a local spalling phenomenon occurs on both sides. The specimen is completely destroyed after $890 \mathrm{~s}$ at a loading rate of $0.5 \mathrm{~mm} / \mathrm{min}$.

(3) The concrete specimen in the in situ loading test exhibits brittle failure based on the evolution and forming characteristics of the deformation field of brittle rock-like materials during the entire compression process. The stress concentration area develops from the upper and lower bottom to fully form the peak stress. After the peak, the internal cracks of the specimen gradually develop to form a longitudinal crack through the upper and lower bottom surface of the crack, producing a mesh spalling crack. The specimen is completely destroyed after $401 \mathrm{~s}$ at $0.5 \mathrm{~mm} / \mathrm{min}$ loading rate.

(4) The failure process of viscous/brittle rock-like materials under compression corresponds to the deformation localization characteristics. At the initial stage of compression, the deformation localization zone begins to expand from the middle area to the surrounding area. In the linear elastic deformation stage, the initial deformation localization cloud map corresponds to the peak failure cloud map. At the peak, the failure cloud map is completely formed and is consistent with the failure entity map. The deformation localization characteristics of rock-like materials can be used to quantitatively describe the compression deformation process.

(5) In this paper, two main components of asphalt and concrete in subgrade were selected for compressive load stability and deformation localization analysis, and the specific damage of subgrade during service was studied. However, it is still necessary to consider the influence of other components to obtain clearer and more comprehensive results. This study has important engineering significance pertaining to the synchronous monitoring of subgrade damage in long-term service conditions.

\section{Data Availability}

The data used to support the findings of this study are available from the corresponding author upon request.

\section{Conflicts of Interest}

The authors declare that they have no conflicts of interest.

\section{Acknowledgments}

This study was supported by the National Natural Science Foundation of China (project number: 51774048) and
Fundamental Research Funds for the Central Universities (project number: FRF-TP-19-009B1).

\section{References}

[1] H. P. Xie, R. D. Peng, and Y. Ju, "Analysis of energy dissipation in the process of rock deformation and failure," Chinese Journal of Rock Mechanics and Engineering, vol. 21, pp. 3565-3570, 2004.

[2] S. Benaboud, M. Takarli, B. Pouteau, and F. Allou, "Fatigue damage monitoring and analysis of aged asphalt concrete using acoustic emission technique," Road Materials and Pavement Design, vol. 22, no. S1, 2021.

[3] O. M. Sakharuk, L. I. Muravs'kyi, I. S. Holyns'kyi, and O. V. Lychak, "Determination of the field of local displacements by the digital speckle correlation method with adaptive segmentation of the images," Materials Science, vol. 49, no. 5, 2014.

[4] Z. B. Zhang, S. J. Li, and X. Y. Qin, "Research on the behavior and mechanism of three-dimensional crack growth under uniaxial loading," Advances in Materials Science and Engineering, vol. 2021, Article ID 5560253, 12 pages, 2021.

[5] X. Z. Sun, F. B. Meng, C. Zhang, and H. Jiang, "Progressive failure and acoustic emission characteristics of red sandstone with different geometry parallel cracks under uniaxial compression loading," Advances in Materials Science and Engineering, vol. 2021, Article ID 5569091, 11 pages, 2021.

[6] Y. S. Ma, W. Z. Chen, D. S. Yang et al., "Experimental study on brittle rock failure based on three-dimensional digital image correlation technology," Geotechnical Mechanics, vol. 38, no. 1, pp. 117-123, 2017.

[7] S. J. Peng, X. M. Ran, J. Xu et al., "Experimental study on localized load rate effect of sandstone deformation based on 3D-DIC technology," Geotechnical Mechanics, vol. 41, no. 11, pp. 3591-3603, 2020.

[8] Y. S. Ma, W. D. Chen, and D. S. Yang, "Experimental study of brittle rock failure based on 3D digital image correlation technology," Rock and Soil Mechanics, vol. 1, no. 38, pp. 117-123, 2017.

[9] D. Caduff, G. Jan, and M. Van Mier, "Analysis of compressive fracture of three different concretes by means of 3D-digital image correlation and vacuum impregnation," Cement and Concrete Composites, vol. 4, 2010.

[10] E. Verhulp, B. vanRietbergen, and R. Huiskes, "A tree-dimensional digital image correlation technique for strain measurements in microstructures," Journal of Biomechanics, vol. 9, 2004.

[11] Y. H. Zhao, H. H. Liang, C. Y. Xiong et al., "Introduced by digital image correlation technology deformation analysis of rock damage," Journal of Rock Mechanics and Engineering, vol. 1, no. 21, pp. 73-76, 2002.

[12] H. L. Xu, H. H. Ren, J. N. Qin, and X. Guo, "Experimental study on structural mechanics of asphalt pavement by digital speckle correlation methods," Mathematical Problems in Engineering, vol. 2020, Article ID 8857369, 5 pages, 2020.

[13] Y. F. Fu, Z. Z. Liang, and C. A. Tang, "Influence of microscopic heterogeneity of rock medium on macroscopic fracture process," Geotechnical Engineering Report, vol. 6, pp. 705-710, 2000.

[14] D. Braz, R. C. Barroso, R. T. Lopes, and L. Motta, "Crack detection in asphaltic mixtures by computed tomography," NDT \& E International, vol. 44, no. 2, 2010. 
[15] H. Zhou, F. Z. Meng, J. J. Lu et al., "Methods for determining crack initiation strength and damage strength of hard rock," Geotechnical Mechanics, vol. 4, no. 35, pp. 913-918, 2014.

[16] C. Zhao, S. Tian, T. H. Song et al., "Research on crack propagation and damage evolution characteristics of rock under uniaxial compression based on global strain field analysis," Rock Mechanics and Engineering Report, vol. 4, no. 34, pp. 763-769, 2015.

[17] Y. Y. Cao, S. P. Ma, and D. Yan, "Dynamic deformation field observation system of rock failure and its application," Geotechnical Engineering, vol. 10, no. 34, pp. 1939-1943, 2012.

[18] L. Shao and Guo, "Experimental study on the influence of strain localization after failure of triaxial specimens," Journal of Geotechnical Engineering, vol. 3, no. 38, pp. 385-394, 2016.

[19] X. L. Wang, P. C. Jiang, S. X. Yan et al., "Study on mechanical properties and deformation field evolution characteristics of layered gneiss," Journal of Mining and Safety Engineering, vol. 37, no. 6, pp. 1255-1262, 2020.

[20] Z. X. Yuan, B. Liu, and L. T. Mao, "CT observation and threedimensional deformation field calculation analysis of concrete under uniaxial compression," Engineering Mechanics, vol. 34, no. 5, pp. 188-197+215, 2017.

[21] Y. H. Han, S. Xie, F. Liu et al., "Analysis of internal microdeformation evolution of recycled concrete based on CT images," Journal of South China University of Technology, vol. 47 , no. 5, pp. 73-80, 2019.

[22] J. Xu, Z. S. Yan, S. J. Peng et al., "Deformation and energy analysis during progressive rock failure," Mining Research and Development, vol. 39, no. 8, pp. 47-53, 2019.

[23] D. M. Zhang, Q. T. Hu, and H. Wang, "Digital speckle experimental study on the localization process of soft rock deformation," Journal of China Coal Society, vol. 4, pp. 567571, 2011.

[24] Y. M. Song, Y. D. Jiang, S. P. Ma et al., "Research on deformation field and energy evolution in the whole process of rock deformation and failure," Rock and Soil Mechanics, vol. 5, no. 33, pp. 1352-1356+13659, 2012.

[25] X. B. Yang, X. X. Han, E. L. Liu et al., "Uniaxial cyclic loading and unloading rock non-uniform deformation evolution characteristics," Journal of China Coal Society, vol. 2, no. 43, pp. 449-456, 2018.

[26] Y. S. Pan and X. B. Yang, "Research on white light digital speckle correlation method of rock deformation and failure localization," Geotechnical Engineering, vol. 1, pp. 98-100, 2002. 